УДК 376.37

\title{
ИЗУЧЕНИЕ СПОСОБОВ ОБРАЗОВАНИЯ ПРОИЗВОДНЫХ СЛОВ У ДОШКОЛЬНИКОВ С ОБЩИМ НЕДОРАЗВИТИЕМ РЕЧИ
}

Градова Галина Николаевна к.п.н., доцент кафедры САФУ им. М.В. Ломоносова Кунникова Ольга Николаевна учитель-логопед МБДОУ Детский сад комбинированного № 116 «Загадка»

Аннотация: в статье рассматривается проблема изучения способов образования производных слов у дошкольников с ОНР; представлена методика изученияи особенности словообразованияу дошкольников с ОНР морфологическим и неморфологическим способами.

Ключевые слова: дошкольники с общим недоразвитием речи, производные слова, морфологический и неморфологический способы словообразования; лексико-семантический, лексико-синтаксический и морфолого-синтаксический метод.

\section{STUDY OF METHODS OF FORMATION OF DERIVED WORDS IN CHILDREN WITH GENERAL SPEECH UNDERDEVELOPMENT}

\section{Gradova Galina Nikolaevna Kunnikova Olga Nikolaevna}

Abstract: the article deals with the problem of studying the methods of formation of derived words in preschool children with ONR; the method study and features of word formation in preschool children with ONR is presented by morphological methods.

Key words: preschool with general underdevelopment speech, derivatives words, morphological and non word formation; morphological lexical-semantic, lexical-syntactic and morphological- syntactic method.

Исследование способов образования производных слов у старших дошкольников с общим недоразвитием речи (ОНР) актуально с целью выявления их особых образовательных потребностей, т.к. недоразвитие 
морфологической стороны речи определяет структуру речевого дефекта при ОНР и в то же время, образования производных слов - это один из главных источников расширения словарного запаса дошкольника.

Установлено, что производные слова - это дериваты, значение и звучание которых обусловлены семантикой и звуковой формой однокоренных слов [1].При этом их образование осуществляется двумя способами:

1) морфологическим - образование производных слов суффиксальным, приставочным, приставочно-суффиксальным, бессуфиксальным методом;

2) неморфологическим - образование производных слов морфологосинтаксическим, лексико-синтаксическим, лексико-семантическим методами.

Доказано, что нормотипичные дети овладевают вышеуказанными способами словообразованияуже в дошкольном возрасте [2]. Однако, у старших дошкольников ОНР наблюдаются замена близких по семантике аффиксов, стойкие ошибки в образовании малознакомых сложных слов, что указывает на нарушения неморфологического способа словообразования [3].

Для изучения способов образования производных слов у дошкольников с ОНРнами разработана методика, включающая два блока экспериментальных заданий, критерии оценки и баллово-уровневые характеристики выполнения заданий.

Блок 1. Исследование сформированности морфологического способа образования производных слов у дошкольников с ОНР.

Задание 1.1. «Кто у кого?».

Цель: исследование суффиксального метода образования существительных (суффиксов -онок-, -ата) у дошкольников с ОНР.

Оборудование: предметные картинки (коза-козленок-козлята, лисалисенок-лисята, волк-волчонок-волчата, слон-слоненок-слонята, медведьмедвежонок-медвежата).

Слова-стимулы: коза-козленок-козлята, лиса-лисенок-лисята, волкволчонок-волчата, слон-слоненок-слонята, медведь-медвежонок-медвежата.

Ход проведения: логопед дает инструкцию: «Посмотри на картинки и ответь на вопросы: «Кто это?», «Как называют детеныша/детенышей?» Отвечая на вопросы, не торопись, подумай». После этого педагог показывает картинки и просит ответить на вопросы.

Образец: Кто это? (лиса) Как называют детеныша лисы? (лисенок) Один лисенок, а если их несколько, как говорят? (лисята). Вопросы задаются с учетом слов-стимулов. 


\section{Задание 1.2. «Большой и маленький».}

Цель: исследование суффиксального метода образования существительных (суффиксы - очк-, -ик-, -ица) у дошкольников с ОНР.

Оборудование: предметные картинки: дом-домик, вилка-вилочка, зонтзонтик, стул-стульчик, цветок-цветочек, яблоко-яблочко, машинамашинка, кошка-кошечка, мяч-мячик.

Слова-стимулы: домик, солнышко, зонтик, стульчик, цветочек, яблочко, машинка, кошечка, мячик.

Ход проведения: педагог дает инструкцию: «Посмотри на картинки с изображением предметов разной величины. Твоя задача: назвать большой и маленький предметы. Например: «Что это?» - дом. «Этот дом большой, а этот?»- маленький. «Назови дом ласково» - домик». Сейчас отвечать будешь ты. Не торопись, подумай». После этого педагог показывает картинки и просит ответить на вопросы. Засчитываются верные ответы на вопрос «назови маленький предмет ласково». Вопросы с учетом слов-стимулов: - Что это? (вилка). Это вилка большая, а это? (маленькая). Назови маленькую вилку ласково (вилочка). - Что это? (зонт). Этот зонт большой, а этот? (маленький). Назови маленький зонт ласково (зонтик). - Что это? (стул). Этот стул большой, а этот? (маленький). Назови маленький стул ласково (стульчик) и т.д.

Критерии оценки заданий 1.1, 1.2.

3 балла - 75\% верных ответов - навык образовывать слова морфологическим способом сформирована: ребенок правильно использует: суффиксы -онок-, - ата, что позволяет ему образовывать названия детенышей животных в единственном и множественном числе, суффиксов - очк-, -ик-, ица-, что демонстрирует его способность образовывать существительные с помощью уменьшительно-ласкательных суффиксов, суффиксов -ий-, - ин-, что позволяет ему образовывать относительные прилагательные.

2 балла - 50\% верных ответов - навык образовывать слова морфологическим способом сформирована частично: ребенок допускает ошибки в применении суффиксов: -онок-, -ата- для названия детенышей животных в единственном и множественном числе, суффиксов - очк-, -ик-, ица-, для образования существительных с помощью уменьшительноласкательных суффиксов, суффиксов -ий-, - ин- для образования относительных прилагательных.

1 балл - менее 50\% верных ответов - навык словообразования 
морфологическим способом не сформирован; ребенок не умеет образовывать слова с помощью суффиксов - очк-, -ик-, -ица-, -онок-, -ата-, -ий-, - ин-.

Блок 2. Исследование сформированности неморфологического способа образования производных слов у дошкольников с ОНР.

\section{Задание 2.1. «Одно слово на двоих».}

Цель: исследование у дошкольников с ОНР навыка словообразования лексико-семантическим методом.

Оборудование: предметные картинки: ручка у дверей, ручка для письма; коса косить траву, девочка с косой; бьет ключ, ключ от замка; строительный кран, кран с питьевой водой; труба - музыкальный инструмент, труба печная; лисички - грибы, лисички - животные; лист бумаги, лист рябины, кисть для рисования, кисть руки.

Слова-стимулы: ручка, коса, ключ, кран, труба, лисички, лист, лук, кисть.

Ход проведения. Ребенку дается инструкция: «Посмотри внимательно на картинки. Твоя задача выбирать картинки, которые называются одинаково, но обозначают разные предметы. Например: картинки лук-овощ и лук оружие. Оба предмета называются лук, но обозначают разное. Теперь ты будешь выбирать. Выбирая картинки, не торопись, будь внимателен». После этого педагог показывает все картинки, ребенок парами находит и называет картинки.

Критерии оценки.

3 балла - 75\% верных ответов - лексико-семантический метод словообразования сформирован: ребенок правильно понимает и употребляет многозначность слов (слова-омонимы).

2 балла - 50\% верных ответов - лексико-семантический методсловообразования сформирован у ребенка частично и нуждается в дальнейшем развитии, ребенок допускает ошибки при употреблении словомонимов, не понимает многозначности слова.

1 балл - менее 50\% верных ответов - навык словообразования лексикосемантическим методом не сформирован; ребенок не понимает и не употребляет слова-омонимы.

\section{Задание 2.2. «Назови правильно».}

Цель: исследование у дошкольников с ОНР навыка словообразования морфолого-синтаксическим методом. 
Оборудование: предметные картинки: мороженое, замороженный листик, Дед Мороз, столовая (помещение), столовая ложка, стол, детская (комната), детская кроватка, дети. Слова-стимулы: мороженое, замороженный листик, дед Мороз, столовая (помещение), столовая ложка, стол, детская (комната), детская кроватка, дети.

Ход проведения. В начале исследования ребенку дается инструкция: «Посмотри на картинки, они звучат похоже. Назови их правильно. Например: часы, часовой механизм, часовой. При подборе слов будь очень внимателен». Логопед предлагает ребенку картинки группами: мороженое, замороженный листик, Дед Мороз; столовая (помещение), столовая ложка, стол; детская (комната), детская кроватка, дети.

Критерии оценки.

3 балла - 70\% верных ответов - ребенок в полной мере владеет навыком образования словморфолого-синтаксическим методом.

2 балла - 50\% верных ответов - навык словообразования морфологосинтаксическим методом сформирован частично.

1 балл - менее 50\% верных ответов - навык словообразования морфолого-синтаксическим методом не сформирован; ребенок не владеет методом словообразования однокоренных слов разных частей речи, допускает много ошибок.

\section{Задание 2.3. «Игра со словами».}

Цель: исследование у дошкольников с ОНР навыка словообразования лексико-синтаксическим методом.

Слова-стимулы: длинноухий, быстроногий, темноволосая, пылесос, остроклювый, мусоровоз, кофеварка, звездопад, мясорубка, самокат.

Ход проведения: педагог дает ребенку инструкцию: «Я буду задавать вопросы, твоя задача - правильно на них ответить. Например: у зайца короткий хвост. Заяц какой? Короткохвостый. Будь внимателен, отвечая на вопросы!». Вопросы с учетом слов-стимулов: - Как называется бытовой прибор, который пыль сосет? - У зайца быстрые ноги. Заяц какой? - У девочки темные волосы. Девочка какая? - Как называется бытовой прибор, который мясо рубит? - Как называется природное явление, когда звезды падают? и т.д.

Критерии оценки.

3 балла - 70\% верных ответов - ребенок владеет лексикосинтаксическим методомсловообразования.

2 балла $-50 \%$ верных ответов - ребенок допускает ошибки при 
выполнении заданий, что свидетельствует о несформированности навыка словообразования слиянием основ слова без опоры на наглядность.

1 балл - менее 50\% верных ответов - допускаются множественные ошибки, навык словообразования лексико-синтаксическим методомне сформирован.

Сумма баллов каждого блока заданий определяет уровень развития словообразовательных навыков: высокий, средний, низкий.

Высокий уровень - 80\% результативности (10 баллов) - дети не допускают ошибок или делают их минимальное количество при образовании слов морфологическим и неморфологическим способами: результативны при образовании существительных с помощью суффиксов онок-, -ата-, очк-, -ик-, ица-,-ий-, - ин; понимают и правильно употребляют слова-омонимы, образуют однокоренные слова разных частей речи и владеют навыком словообразования слиянием основ слова без опоры на наглядность.

Средний уровень - более 50\% результативности, более 7 баллов недостаточно сформированы навыки образования слов морфологическими неморфологическим способами: дети допускают ошибки в применении суффиксального способа словообразования существительных (с помощью суффиксов онок-, -ата-, очк-, - ик-, -ица-); кроме того, недостаточно сформирован навык правильного употребления слов-омонимов, навык образования однокоренных слов и навык образования слов путем слияния основ.

Низкий уровень, 50\% и менее результативности (менее 6 баллов) - дети допускают множественные ошибки, навыки словообразования слов морфологическим и неморфологическим способами не сформированы: дети не умеют образовывать слова суффиксальным способом, не понимают словаомонимы и неправильно их употребляют, не могут образовывать родственные слова разных частей речи и не владеют навыком образования слов, основанном на слиянии основ слов без опоры на наглядность.

Представляем результаты экспериментального исследования, проведенного группе компенсирующей направленности для детей с ОНР МБДОУ «Детский сад № 116 «Загадка» г. Архангельска. В экспериментальную группу (ЭГ) включены старшие дошкольники с ОНР III уровня, контрольную группу (КГ) - нормотипичные дошкольники старшего дошкольного возраста.

При обработке результатов первого блока, направленного на 
исследование сформированности морфологического способа образования производных слов у дошкольников с ОНР получены следующие данные (Рис.1).

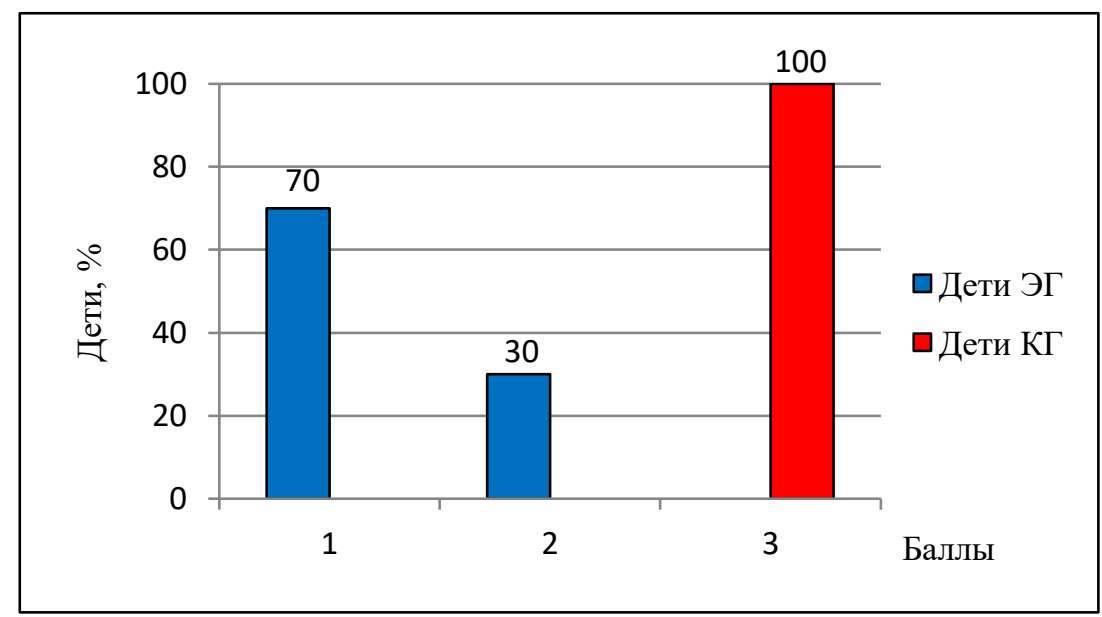

\section{Рис. 1. Исследование сформированности морфологического способа образования производных слов у дошкольников с ОНР}

Результаты 70\% детей ЭГ соответствуют 1 баллу, т.е. дети не способны образовывать существительные и прилагательные суффиксальным способом. Показатель 30\% детей ЭГ соответствует 2 баллам, что значит навык словообразования морфологическим способом сформирован частично. Данные показатели не характерны для детей КГ. Для ответов детей ЭГ характерны ошибки: в применении суффиксов -онок-, -ата-: «козлики», «лисенки», «медведик», «медвежонки»; в применении суффиксов -ик-, -очк-, ица-: «стулик», «котеночек», «яблочек», «машиночка»; в применении суффиксов -ий, -ин-: «ослячий», «поросиный», «медвединый», «белкин». Качественная оценка результатов детей КГ, позволяет сделать вывод, что в отличие от детей ЭГ, навык словообразования морфологическим способом у данной категории детей сформирован.

При обработке результатов второго блока (исследование сформированности неморфологического способа образования производных слов у дошкольников с ОНР), а именно, привыявлении умения выделять слова, образованные лексико-семантическим методом были получены следующие данные (Рис.2). 


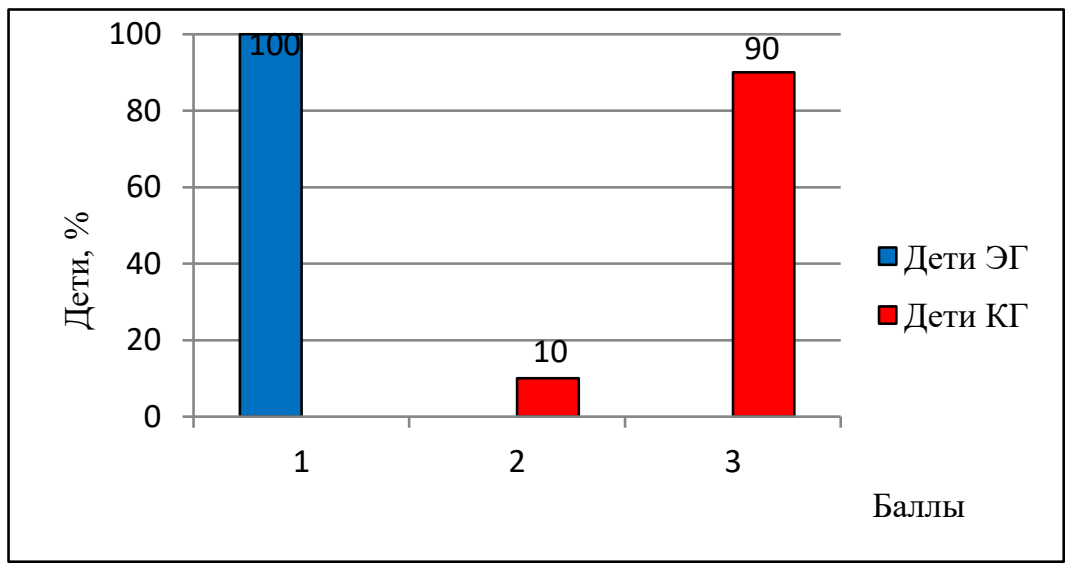

\section{Рис. 2. Исследование у дошкольников с ОНР образования производных слов лексико-семантическим методом}

Дети ЭГ показали результаты характерные для 1 балла, что не свойственно для детей КГ. Полученные данные свидетельствуют о несформированности навыка словообразования лексико-семантическим методом, дети не понимают значение слов-омонимов и неправильно их употребляют. Задание для этой группы детей оказалось сложным: дети либо отказывались от выполнения заданий, либо выполняли неверно. Правильные ответы чаще всего появлялись к 4-5 ряду слов. Показатели детей КГ соответствуют 2 и 3 баллам, они не допускают ошибок при употреблении слов-омонимов или делают их минимальное количество (владеют навыком лексико-семантического метода словообразования).

При диагностике умения образовыватьпроизводные слова морфологосинтаксическим методом были получены следующие данные (Рис.3).

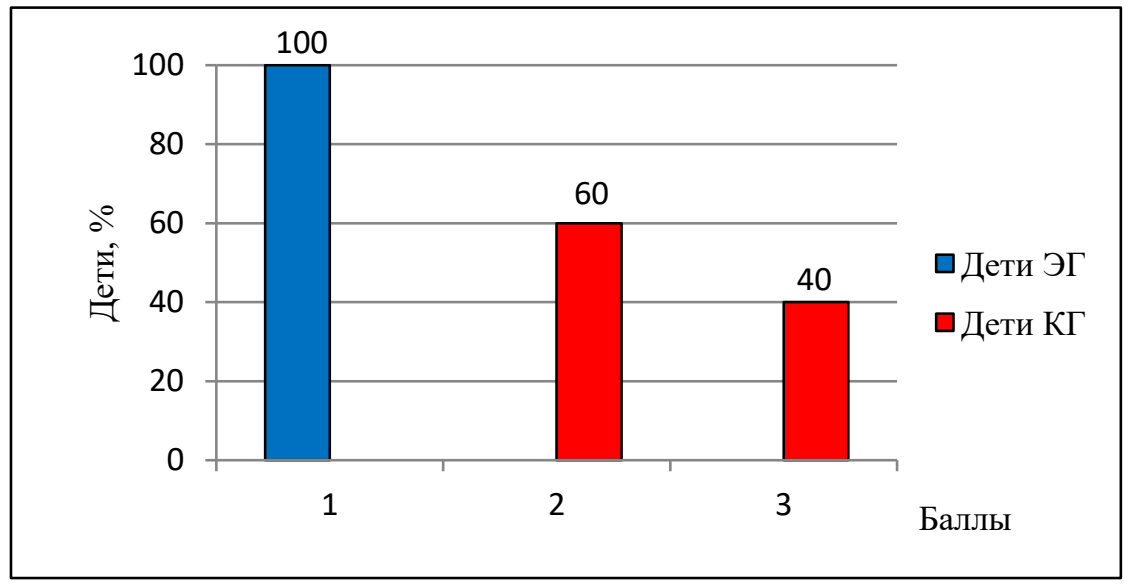

Рис. 3. Исследование у дошкольников с ОНР образования производных слов морфолого-синтаксическим методом 
Дети ЭГ показали результаты 1 балла, что не характерно для КГ, что означает, что дети не могут подобрать однокоренные слова с опорой на наглядность. Они называли существительные (Дед Мороз, стол, дети), но образовать от них однокоренные слова было сложной задачей. Иногда дети просто угадывали правильный ответ, называя то, что видят на картинке. Навык словообразования данным способом не сформирован. Дети КГ показали результат на 2 и 3 балла, что означает точное выполнение заданий или с небольшим количеством ошибок. Дети тщательно подбирали правильное слово, прежде, чем его назвать. Выбор правильного ответа, из произнесенных вслух, дети делали самостоятельно.

При выявлении умения образовывать слова лексико-синтаксическим методом без опоры на наглядность были получены данные (Рис. 4).

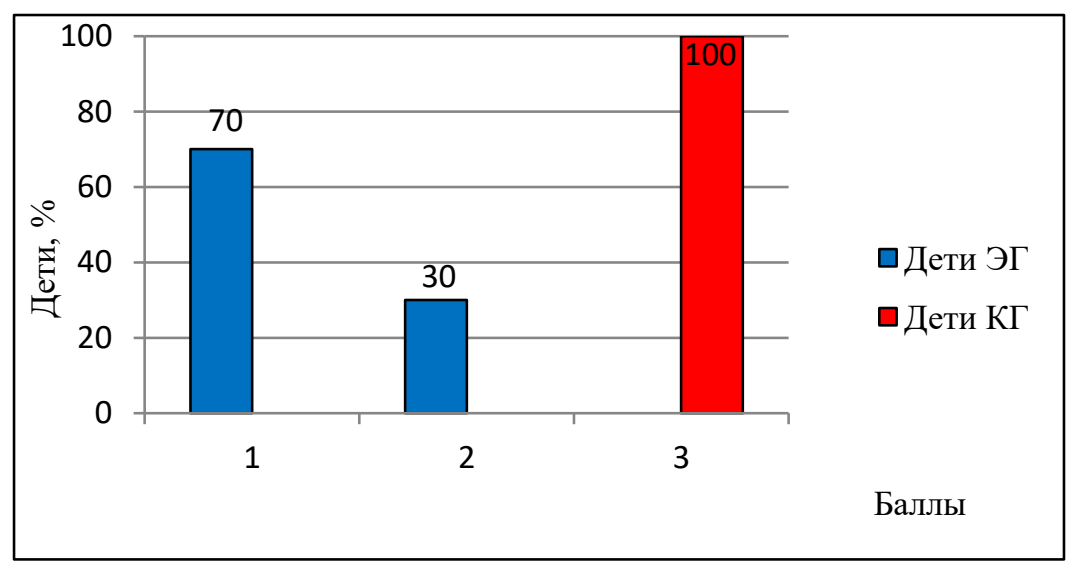

\section{Рис. 4. Исследование у дошкольников с ОНР образования производных слов лексико-синтаксическим методом}

Дети ЭГ показали результаты на 1 и 2 балла, что отличается от детей КГ, результаты которых выше. Дети ЭГ (70\%), набравшие правильных ответов только на 1 балл, навыком образования слов путем слияния основ не владеют.30\% детей ЭГ допускают ошибки при выполнении заданий. Наиболее характерные ошибки в этом задании: «зайценогибыстрые», «темными волосами», «мусоровозилка», «длинноушей». Часто дети повторяли задание: жираф с длинной шеей, девочка с волосами. Самыми доступными словами для детей ЭГ оказались слова «листопад», «мусоровоз» и «звездопад». Ни один ребенок ЭГ не смог образовать слово «длинноухий». Дети КГ показали результат на 3 балла, что говорит о сформированности навыка словообразования данным методом. Дети способны образовывать новые слова 
путем слиянием основ без опоры на наглядность. В данном задании больше всего ошибок дети делали в словах: темноволосая, длинноухий. В нескольких случаях дети, затрудняясь дать ответ, отказывались отвечать на первые вопросы, но потом понимали, как именно образовывать слова данным способом и легко справлялись с дальнейшими заданиями.

Экспериментальные данные позволили описать уровни сформированности навыка словообразования у старших дошкольников с ОНР (Рис.5).

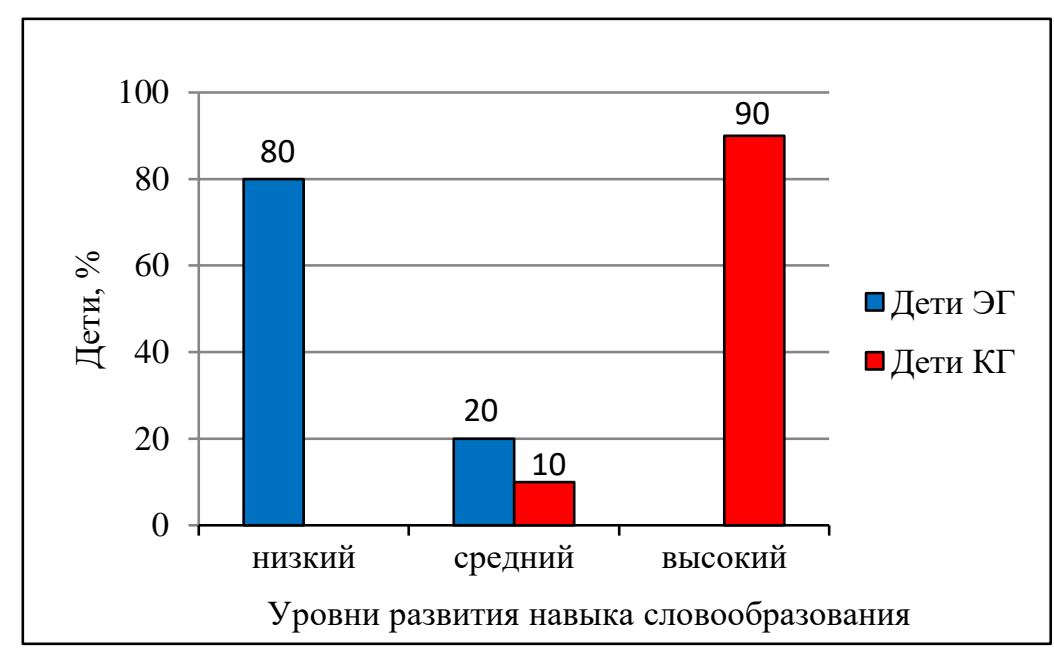

\section{Рис. 5. Уровни сформированности навыка словообразования у старших дошкольников с ОНР}

Диаграмма указывает, что дети ЭГ показали результат, соответствующим низкому ( $80 \%$ детей) и среднему (20\% детей) уровням. Для детей данной категории характерны множественные ошибки. Навык словообразования слов морфологическим и неморфологическим (лексикосемантическим, лексико-синтаксическим, морфолого-синтаксическим) способами находятся на низком уровне. Легче всех дети ЭГ образовывали слова морфологическим способом. На протяжении всего эксперимента, наиболее характерными ошибками для детей ЭГ были: неверное образование слова, отказ от выполнения задания, повтор задания экспериментатора, использование слов-заменителей. Трудности вызвало задание на выявление умения образовывать слова морфолого-синтаксическим способом.

Дети КГ показали результат, который соответствует высокому (90\%) и среднему (10\%) уровням; дети КГ владеют навыками словообразования морфологическим и неморфологическим способами. Они правильно образуют существительные суффиксальным способом, понимают и правильно 
употребляют омонимы, правильно образуют новые слова путем слияния основ, а также способны образовать однокоренные слова разных частей речи.

Таким образом, при образовании производных слов у дошкольников с ОНР в ходе исследования были выявлены специфические особенности, нехарактерные для их сверстников с нормальным речевым развитием.

Кроме того, исследование доказало, что производные слова, образованные морфологическим способом,усваиваются детьми лучше. Именно этот способ характерен для образования новых слов старшими дошкольниками с ОНР. Хотяпоказатели изучения данного способа словообразования и не достигают высокого уровня, но при образовании новых слов именно эти способом, было допущено всех меньше ошибок. Из неморфологических способов словообразования дети могут усвоитьлексикосинтаксическийметод, т.к. результаты изучения образовывать слова данным методом выше, чем лексико-семантическим и морфолого-синтаксическим методами.

Итак, результаты изучения способов образования производных слов у дошкольников с ОНР указывают на необходимость создания специальных образовательных условий по их формированию.

\section{Список литературы}

1. Жеребило Т.В. Термины и понятия. Изд. 5-е, испр. и доп. - Назрань: ООО «Пилигрим», - 2010. - 486 с.

2. Вершинина О.М. Особенности словообразования у детей с общим недоразвитием речи III уровня // Логопед. — 2004. - №1 - - С. 34-40.

3. Туманова Т.В. Развитие словообразования у дошкольников и младших школьников с общим недоразвитием речи //Воспитание и обучение детей с нарушениями развития. - 2003. — №6. - С. 24-28.

(C) Г.Н. Градова, О.Н. Кунникова, 2021 